\title{
Dispuestos a trabajar. Aproximación a la visión de los agentes estatales de un programa de empleo para jóvenes en Argentina
}

\section{Willing to Work. An Approach to the Views of Youth Employment Program State Agent's in Argentina}

\author{
Gonzalo ASSUSA \\ Consejo Nacional de Investigaciones Científicas y Técnicas (Argentina) \\ gon_assusa@hotmail.com
}

Recibido: 10 de julio de 2013

Aceptado: 11 de marzo de 2014

\section{Resumen}

El presente artículo propone un análisis de los discursos, diagnósticos y lógicas de funcionamiento que estructuran el Programa Jóvenes con Más y Mejor Trabajo en un barrio popular de Córdoba, Argentina. El texto indaga sobre la manera en la que este programa (a partir de sus diferentes dimensiones e instancias) participa en la configuración de la "cultura del trabajo" de jóvenes de clases populares. A partir de esto, describimos los sentidos y reformulaciones de algunos ejes conceptuales del programa y su puesta en práctica por agentes estatales. De esta manera, mostramos el entrecruzamiento de la producción de legitimidades del Estado (autoridad moral) y legitimidades de los beneficiarios del programa (mérito y dignidad social), en un proceso móvil cuya regulación hegemónica lo constituye en marco discursivo común para la diferenciación social.

Palabras clave: Cultura del Trabajo; Jóvenes; Políticas de Empleo; Clases Populares; Hegemonía.

\begin{abstract}
This article analyzes the discourses, diagnosis and operational logics embedded in the Programa Jóvenes con Más y Mejor Trabajo developed in a popular district of Córdoba, Argentina. The text digs in the way the program (from its different dimensions and levels) shapes the "culture of work" among young people in popular classes. Then I describe the meanings and conceptual reformulations of some aspects of the program and its implementation by state agents. Subsequently, I elucidate the interrelations between the productions of legitimacy, having on the one side the State (moral authority) and on the other the beneficiaries (social merit and dignity). This is a dynamic process defined as a common discursive framework for social differentiation by its hegemonic regulations.
\end{abstract}

Keywords: Culture of Work; Youth; Employment Policies; Popular Classes; Hegemony. 
Referencia normalizada: Assusa, G. (2014). Dispuestos a trabajar. Aproximación a la visión de los agentes estatales de un programa de empleo para jóvenes en Argentina. Revista de Antropología Social, 23, pp. 181-208.

SUMARIO: 1. Introducción. 2. ¿Desde arriba o desde abajo? Elementos teóricos desde la antropología de la política. 3. Del problema del desempleo al problema de la empleabilidad. 4. El Programa. 5. La gestión de la empleabilidad: la visión de la burocracia. 5.1. El diagnóstico. 5.2 La política activa y el "trabajo artesanal". 5.3. Diferencia entre las políticas activas y el "asistencialismo" o políticas pasivas. 6. Palabras finales: legitimidad política y cultura del trabajo. 7. Referencias bibliográficas.

\section{Introducción ${ }^{1}$}

El trabajo como concepto de síntesis sobre la posición ocupada en la estructura de la sociedad fue históricamente un punto neurálgico de intervención social, eminentemente politica (con la consolidación del Estado de Bienestar y la sociedad salarial) pero también moral. La construcción de este núcleo de regulación social motivó y movilizó fuertes castigos a aquellos que, excluidos del mundo del trabajo moderno, eran considerados "viciosos y peligrosos". Pero también promovió la construcción de concepciones que ligaban y esencializaban el vínculo entre mundo popular y trabajo: "la necesidad del trabajo estaba inscripta en un complejo que se podría denominar 'antropológico' (indisociablemente religioso, moral, social y económico), que definía la condición popular en su oposición a las situaciones privilegiadas" (Castel, 2000: 172). Esta cruzada contra el no-trabajo fue haciéndose con el tiempo menos restrictiva y crecientemente "activa"

Las políticas de empleo de la última década en Argentina se construyeron en torno a la noción de "empleabilidad". El período que arranca en el gobierno de Eduardo Duhalde en el año 2002 se caracteriza no sólo por una gran mutación de las dinámicas del mercado de trabajo en Argentina (definida fundamentalmente por una radical disminución del empleo y del subempleo), sino también por esa profunda transformación en la racionalidad de gestión estatal del problema del empleo y desempleo. El lugar que se le asigna al mundo del trabajo en este nuevo cuerpo de

\footnotetext{
${ }^{1}$ Muchos de los materiales de investigación que aquí presento fueron discutidos, relevados y compartidos con María Gabriela Brandán Zehnder. De esas discusiones surgieron la base de las ideas del texto. Todo error que pueda aparecer en el mismo corre por responsabilidad exclusivamente del autor. Agradezco a Virginia Manzano, en cuyo seminario desarrollé la primera versión de este texto. También a Cecilia Inés Jiménez Zunino, quien leyó detenidamente y criticó el escrito preparado para la publicación. Por último, a María Audisio, quién me obligó a repensar - sin resolver - el sentido de la escritura misma del texto.

${ }^{2}$ Utilizamos la noción de "activo", como detallaremos a continuación, no sólo en su sentido técnico (asociado a la perspectiva de las políticas activas), sino también en relación a su uso nativo en el campo que estudiaremos. Como veremos, la actividad se vincula, como actitud, a una serie de valores positivos en torno al trabajo (mérito, voluntad, esfuerzo) y se opone a problemas culturales que iremos describiendo y analizando a lo largo del texto (como la pasividad, la vagancia, el asistencialismo, etc.).
} 
políticas sociales y laborales lo ubica en el centro de un complejo simbolismo político que articula discursivamente la inclusión social y la ciudadanía. En este marco, las políticas de empleo para jóvenes adquieren una relevancia fundamental, en la medida en que el peso particular del trabajo interseca con lo que se entiende es un momento biográfico clave: el paso de la adolescencia a la adultez y la incorporación a la vida pública.

Por su parte, esta particular franja sociodemográfica — la juventud - ha sido chivo expiatorio y preocupación fundamental en el discurso político y se ha colocado entre los temas con mayor presencia de la agenda pública y de los medios de comunicación: delincuencia, inseguridad, consumo de drogas, crisis moral, etc. Todo un objeto de pánico moral (Cohen, 2002), fundamentalmente en lo referido a su composición de clase y a los símbolos identificados a la cultura popular ${ }^{3}$.

En un contexto en el que las dos fuentes de miedo social se entrecruzan (una población en edad peligrosa, y la peligrosidad del no-trabajo), llevamos adelante una investigación sobre la configuración de la "cultura del trabajo" en jóvenes de un barrio popular de la ciudad de Córdoba, Argentina. Esta noción aparece primero en los estudios antropológicos y sociológicos ligada a la de "cultura obrera" (Hoggart, 2013; Novelo, Gómez y Castro, 1986). Con las transformaciones que el posfordismo y la denominada crisis de la sociedad industrial le imprimió a la organización del trabajo, las investigaciones viraron hacia una aprehensión de realidades y procesos más complejos y heterogéneos, y se adscribieron a las nociones de "culturas laborales" (Guadamarra Olivera, 2000) y "culturas del trabajo" (Palenzuela, 1995; Moreno Navarro, 1997). Estas conceptualizaciones tuvieron en común el hecho de entender las culturas del trabajo como producciones simbólicas en términos de patrimonios culturales de grupos sociocupacionales o clases sociales empíricamente identificables.

El objetivo de nuestra investigación es comprender la "cultura del trabajo" no ya como una elaboración autónoma y sustancializada de los jóvenes de sectores populares, sino como una producción conflictiva y relacional de un horizonte común de significaciones de la que ellos forman parte: una configuración cultural (Grimson, 2011). A partir de esto, comenzamos a preguntarnos por aquellas instituciones, dispositivos y prácticas a partir de las cuales las agencias estatales establecen regulaciones a las prácticas laborales en términos de "cultura del trabajo". En este marco, emprendimos un trabajo de indagación (al que dedicamos el presente texto) sobre las prácticas y representaciones de los agentes estatales participantes del Programa

${ }^{3}$ Tal como lo plantean Míguez e Isla: "el Otro demonizado como factor de temor e inseguridad está constituido por 'los jóvenes' más que por el extranjero. Pero no 'los jóvenes' en tanto simple grupo etario, sino por aquellos especialmente pobres, con sus estéticas y consumos musicales diferentes, que manipulan la pantalla de televisión o de juegos electrónicos. Parecería que los programas que consumen son muy violentos a los ojos adultos, tanto que este factor incidiría en la imagen de inseguridad que suscitan. Así, los jóvenes construidos como alteridad lejana y peligrosa son uno de los elementos que afectan mucho el temor al crimen, además de exponerlos como sector fuertemente estigmatizado y vulnerable" (2010: 96). 
Jóvenes con Más y Mejor Trabajo (PJMyMT) del Ministerio de Trabajo, Empleo y Seguridad Social de la Nación (MTESS) en Córdoba Capital.

La política, como pudimos observar en nuestro trabajo de campo, participaba activamente de esta configuración ${ }^{4}$. De esta manera, pudimos acceder a una comprensión más acabada de la complejidad intrínseca de la puesta en práctica de este tipo de políticas y de la heterogeneidad de apuestas, acciones y valores que constituyen su funcionamiento, y sobre la manera en que esta complejidad estructura el aporte específico de estas formaciones estatales a la producción del problema de la empleabilidad juvenil. Con este objetivo, comenzaremos reconstruyendo algunas discusiones sobre el Estado y la cultura popular que articulan desarrollos teóricos clásicos y aportes de raíz gramsciana. Luego, analizaremos el contexto en el cual la noción de "empleabilidad" pudo constituirse en faro de la intervención política sobre el problema del empleo en Argentina, y la particularidad de esta conceptualización para pensar la problemática laboral vinculada a la juventud. En un tercer momento, describiremos los rasgos generales del PJMyMT y los supuestos que estructuran su letra. Posteriormente, analizaremos algunas características de las prácticas y discursos de los agentes estatales que componen el equipo técnico y los funcionarios ministeriales dedicados a este programa, fundamentalmente en lo referido a: 1) su diagnóstico del problema de la "empleabilidad"; 2) la definición de su propia actividad a partir de las nociones de "técnica", "orientación" y "personalización"; y 3) las diferencias que estos agentes construyen entre este programa y las políticas sociales que lo precedieron. Por último, identificaremos algunos puntos de acceso epistemológico a una configuración de la "cultura del trabajo" que muestra cruces y articulaciones de legitimidades vinculadas tanto al Estado como a los jóvenes de sectores populares.

${ }^{4}$ La estrategia metodológica de nuestra investigación propone una articulación y triangulación de técnicas cualitativas y cuantitativas. Para este texto se utiliza el material correspondiente a 15 entrevistas en profundidad a trabajadores en el área ministerial y del equipo técnico a cargo de PJMYMT. Esto nos permitió un acceso al punto de vista técnico o especialista en el campo respecto de la política y su funcionamiento. Las entrevistas se realizaron en los lugares de trabajo de las oficinas, durante el segundo semestre de 2011 y el primero de 2012. A diferencia de los trabajadores del ministerio (empleados contratados), todos los integrantes del equipo técnico se encontraban bajo una condición contractual precaria e inestable (monotributistas o autónomos), salvo su coordinador, un empleado registrado y estable de la planta municipal. Si bien puede constituir una particularidad del funcionamiento del programa en la ciudad de Córdoba, la selección del personal para estas funciones parece orientarse casi siempre a profesionales de carreras de ciencias sociales (trabajo social, comunicación social, ciencias políticas, sociología, psicología, etc.), o bien, personas que hayan tenido experiencia en trabajo comunitario o proyectos con jóvenes, trabajo con "sectores vulnerables", etc. El número de entrevistas realizadas abarca la mayor parte del universo del equipo técnico en la ciudad, por lo que no se aplica ningún criterio de muestreo para su selección. También incluimos en el texto análisis documentales de informes y materiales de formación de distintos organismos públicos dedicados a la cuestión de las políticas laborales. Actualmente, en nuestro trabajo de campo, se encuentran en curso las indagaciones en torno a las prácticas, las significaciones y las trayectorias de los jóvenes beneficiarios del programa. 


\section{2. ¿Desde arriba o desde abajo? Elementos teóricos desde la antropología de la política}

Recurrimos a elaboraciones conceptuales de la antropología de la política, puesto que si la mayoría de los constructos teóricos sobre la "cultura del trabajo" se centraba en lo sucedido en el marco del proceso de trabajo y en los emergentes simbólicos del mundo de la fábrica, nuestro trabajo de campo se orientaba hacia el afuera del espacio específicamente laboral. Este se desenvolvía en aquellas instancias de formación (Martín Criado, 1999) que, desde algunas agencias estatales, producian el problema de la empleabilidad juvenil, e intervenían en la regulación de las prácticas y hábitos de una población de jóvenes definida como vulnerable. Pero como mostraremos a lo largo del escrito, no basta con establecer los términos formales de la política para comprender la manera en la que produce problemas, realidades y clasificaciones: nuestro abordaje de la cuestión de la "cultura del trabajo" puso en evidencia una compleja red de mediaciones y reinterpretaciones que se activa en la efectiva puesta en práctica de esta política (en los distintos niveles de aplicación y de agentes burocráticos).

En este sentido, si el trabajo y los hábitos y valores asociados a él se vuelven centrales para la valorización social de los jóvenes de sectores populares, es en parte a partir de acciones y discursos de un conjunto de agentes específicamente dedicados a solucionar el problema de la empleabilidad. En su hacer, éstos participan de un proceso más amplio de regulación cultural de las prácticas laborales y de la legitimidad social (prestigio) asociada a las mismas. Por esto, necesitamos desentrañar conceptualmente los vínculos establecidos entre el Estado y sus formaciones, y la "cultura del trabajo" como noción legitimadora a la que se recurre en la producción del problema y la solución de la empleabilidad juvenil.

Según Corrigan y Sayer (2007), el Estado, a partir de la materialidad de sus formaciones, de sus programas, agencias y oficinas, regula las identidades y subjetividades y legitima a través de sus rituales de mando, confiriendo autoridad al poder establecido. En este sentido, el proceso de formación del Estado es leído por estos autores como una revolución cultural, de la misma manera en la que fue leída la formación histórica del capitalismo.

Llamamos a esto regulación moral: un proyecto de normalizar, volver natural, parte ineludible de la vida, en una palabra 'obvio', aquello que es en realidad el conjunto de premisas ontológicas y epistemológicas de una forma particular e histórica de orden social. La regulación moral es coextensiva con la formación del Estado y las formas estatales siempre están animadas y legitimadas por un ethos moral específico (Corrigan y Sayer, 2007: 46).

Su recorrido teórico recupera a Durkheim $(1985,2003)$ — por la relevancia que el clásico le otorgaba al carácter moral de la política-, aunque, a diferencia de éste, piensan que el objetivo de la regulación moral no sería ya la integración de la sociedad, sino la imposición de una dominación legítima (Corrigan y Sayer, 2007: 48). Corrigan y Sayer entienden que en el contexto de la formación social capitalista, la función de la disciplina moral de las formas estatales se corresponde con 
la imposición de una (necesaria) racionalidad práctica (Weber, 2006) que incluye tanto la búsqueda de ganancia como la disciplina de trabajo (Corrigan y Sayer, 2007: 63). En este sentido, las formas estatales actúan, antes que sobre las creencias de los individuos, sobre la capacidad de los sujetos para aplicar determinadas formas de racionalidad a su conducta. Los dispone a actuar de cierta manera (en el caso que analizamos, produce disposiciones para el trabajo).

Shore, en consonancia con estas ideas, sostiene que las políticas públicas influyen sobre las categorías del individuo y de la subjetividad, inculcando hábitos de autogestión y autorregulación (Shore, 2010: 36). Como veremos, la regulación de las prácticas en términos de "incorporación de hábitos" aparece como una dimensión fundamental de las políticas de empleo y del proceso de moralización que intentan desarrollar sobre sus beneficiarios. En la misma dirección, Roseberry sostiene que

Desde su punto de vista [de Corrigan y Sayer], el poder del Estado descansa no tanto en el consenso de sus dominados, sino en las formas y órganos normativos y coercitivos del Estado, que definen y crean ciertos tipos de sujetos e identidades mientras niegan y excluyen otros [...] a través de sus funcionarios y sus rutinas, sus procedimientos y formularios de impuestos, licencias y registros (Roseberry, 2002: 216).

Por ello, estos autores entienden que las políticas públicas intervienen sobre la regulación de las clasificaciones sociales y, en este acto, construyen u objetivan, con estas categorías, a los sujetos a quienes se dirigen (Shore, 2010: 45). Tal como Corrigan y Sayer sostienen, "el Estado se ocupa activamente, incluso muchas veces por la fuerza, de normar las clasificaciones sociales de la civilización capitalista, y su funcionamiento de rutina las vuelve palpables" (Corrigan y Sayer, 2007: 81). En nuestro caso, las categorías de "inempleable", "necesitado", "vocacional", "positivo", establecerán de alguna manera limitaciones y pesarán sobre las trayectorias de los jóvenes sobre los cuales se apliquen.

Con el objetivo de asir teóricamente esta dimensión moral del Estado, Roseberry se desplaza desde la noción de hegemonía a la de procesos hegemónicos para subrayar su devenir antes que su cristalización como resultado. De esta manera, se desmarca de las versiones más "consensualistas" del concepto de hegemonía, construyendo una noción a la vez material y política, pero fundamentalmente frágil de los procesos hegemónicos, para dar cuenta de un cuerpo de prácticas dispuesto para la constitución y establecimiento de un marco discursivo común. Este marco aparece como la estructuración de significados del espacio de la lucha por la hegemonía: "lo que la hegemonía construye no es, entonces, una ideología compartida, sino un marco común material y significativo para vivir a través de los órdenes sociales caracterizados por la dominación, hablar de ellos y actuar sobre ellos" (Roseberry, 2002: 220). En la misma línea de argumentación, Sayer (2002) sostiene que más que una "manipulación de las creencias", la hegemonía "define los límites de lo posible", y en algún sentido, los límites de la lucha. En nuestro análisis, esta afirmación resulta central: las formaciones estatales establecen algunas fronteras dentro de las 
cuales se producen sentidos en torno al problema del empleo juvenil en términos de "cultura del trabajo". Sin embargo, esto no le arroga al Estado la capacidad de fijar absolutamente estos sentidos: encontraremos diferentes desplazamientos y significaciones, no sólo entre agentes estatales y beneficiarios, sino también entre los distintos niveles de las formaciones burocráticas, a partir de sus desiguales posiciones.

Estas críticas y reformulaciones de las maneras de pensar el Estado y los procesos hegemónicos abren nuevas posibilidades para asir las complejas luchas que se traman para producir, construir y apropiarse de los recursos de autoridad y legitimidad. En relación a este área problemática, Roseberry referencia los estudios de Thompson (1991) sobre los motines de la multitud para recordar la manera en que los procesos de lucha se inscriben en el marco de ciertas tradiciones. Esto resulta iluminador para analizar las maneras en las que ciertas políticas públicas (y los agentes que las sostienen y ponen en funcionamiento) producen, reconstruyen y recuperan nociones legitimadoras (Manzano, 2007) estructuradas en marcos discursivos comunes (como el de la "cultura del trabajo" en nuestro país) con fines diversos y ambivalentes. Tal como sostiene Shore, "como los mitos, las políticas públicas ofrecen narrativas retóricas que sirven para justificar —o condenar-el presente, y algo más usual, para legitimar a quienes están en posiciones de autoridad establecidas" (Shore, 2010: 32).

A partir de esta trama categorial leeremos las prácticas y representaciones de los agentes del PJMyMT en el contexto de procesos hegemónicos que regulan la vinculación con el mundo del trabajo de jóvenes de sectores populares, haciendo uso de las nociones legitimadoras propias del campo discursivo de la "cultura del trabajo". Pasaremos revista, ahora, al proceso histórico en el cual estos usos se volvieron posibles.

\section{Del problema del desempleo al problema de la empleabilidad}

La transición de la convertibilidad a la post-convertibilidad ${ }^{5}$ desde el punto de vista del empleo en Argentina, implicó el paso de un mercado de trabajo en retracción, con altas tasas de desempleo y subempleo, a un mercado en franca recuperación, con una fuerte creación de nuevos puestos de trabajo de calidad, calificación y formalización variable. Si bien en este período las tasas de desempleo disminuyeron para todas las edades, la diferencia entre el desempleo en jóvenes y en adultos aumentaron en los últimos años ${ }^{6}$. La juventud sigue accediendo, en un contexto relati-

${ }^{5}$ La literatura sociológica denomina como post-convertibilidad el período que va desde el año 2003 (posterior a la transición luego de la crisis del 2001) hasta la actualidad. La misma se caracteriza en términos generales, y en contraposición al período de la convertibilidad de la década de 1990, por una política monetaria con un tipo de cambio alto y estable (Pérez, 2006), una recuperación de la economía real como eje del régimen de valorización del capital (Basualdo, 2009), y una fuerte recuperación de los niveles de empleo, con la consiguiente caída de la tasa de desempleo, desde el $20 \%$ en su punto más alto en 2002, a estabilizarse alrededor de 6 o $7 \%$ en la actualidad.

${ }^{6}$ Para el año 2009, la tasa de desocupación de las personas entre 15 y 34 años llega al 30\%, muy por debajo del nivel al que había llegado durante los años 2001, 2002 y 2003, pero bastante 
vamente favorable, a empleos más precarios, inestables, sin protección laboral y de menores salarios (Pérez, 2010).

El cambio de época marca también un viraje en cuanto a las preocupaciones de la política laboral: ya no eran los desempleados en situación de riesgo aquellos sujetos en el centro de la escena pública, sino los in-empleables, poblaciones vulnerables que no habían podido incorporarse a los beneficios del mundo del trabajo en el período de crecimiento.

Atravesada la crisis y el período de transición que se prolongó desde 2001 a 2003, se sumó un problema que pasó al centro de la escena pública: el de los "planes sociales". Estas políticas sociales de transferencia o sostenimiento de ingresos fueron atacados desde ciertos sectores políticos y desde buena parte de los medios de comunicación como causantes fundamentales de un des-incentivo de la fuerza de trabajo para la búsqueda de empleo, y por lo tanto, como un poderoso atentado contra la mentada "cultura del trabajo", históricamente formada en Argentina ${ }^{7}$. Entre ellos, el más importante, por su masividad y visibilidad, fue el Plan Jefes y Jefas de Hogar Desocupados (PJJHD) ${ }^{8}$, dependiente de la Gerencia de Empleo y Capacitación Laboral (GECAL). Algunos estudios señalan que el plan vino a funcionar como un paliativo coyuntural para las necesidades básicas de sectores empobrecidos y, al mismo tiempo, como una forma de contención de la protesta social (Andrenacci, Ikei, Mecle et al, 2006).

Ya en el nuevo período (en la gestión de gobierno de Néstor Kirchner que comienza en 2003), el discurso y la estrategia de legitimación política le otorgan un lugar central al trabajo, en el marco de una tradición política como el peronismo, de interpelación a los ciudadanos en tanto trabajadores. Tal como lo plantean Kessler y Cortés,Una variable política y otra ideológica sustentan la estrategia social del período. La primera, la alianza con los sindicatos que da un papel central a las políticas para asalariados formales. Las negociaciones colectivas, el incremento del salario real y la derogación de leyes de flexibilidad laboral de los 90 mejoraron sensiblemente la situación de estos trabajadores. La segunda, marcando un corte radical con el pasado, el gobierno confiaba volver a la 'cultura del trabajo' con un

por encima del nivel de desempleo general para ese año (alrededor del 9\%) (Nefa, Oliveri y Persia, 2010).

7 "Esta nueva cuestión social — presente en los países centrales, pero con mayor crudeza en América Latina - se patentiza como exclusión interna. En Argentina, a la situación anterior se suma el peso de la pérdida de vigencia de una fuerte tradición en la que el Estado apareció como garante de la cohesión social. En efecto, la integración social se estructuró históricamente a partir de dos ejes: el Estado y la Nación, sostenidos alrededor de la cultura del trabajo. Es así que la inserción social a partir de los frutos del trabajo no sólo nutrió el imaginario de los inmigrantes europeos en el inicio de nuestra nacionalidad, sino que acompañó el proceso de integración de los migrantes internos y de países limítrofes desde la década de 1930" (García Raggio, 1998: 16-17).

${ }^{8}$ Para el año 2003, esta política social supera el millón de beneficiarios. Con los años, su número de beneficiarios decreciendo y su modalidad fue progresivamente reemplazada por otro formato de políticas, de tipo universalistas y centrada en un discurso de construcción de ciudadanía y derechos, antes que en el del desarrollo humano de los pobres. Más allá de su progresiva desaparición y reemplazo, el PJJHD quedó en el imaginario y en la opinión pública como objeto de impugnación y preocupación moral hasta la actualidad. 
'giro productivo' que absorbiera la población asistida; ambición que distintas coyunturas obligarían a atenuar (Cortés y Kessler, 2013: 252-253).

En el contexto de la post-convertibilidad, el diagnóstico respecto de la problemática del empleo juvenil realizó un viraje, si bien el paradigma de la empleabilidad se había comenzado a aplicar desde los años noventa. Fuertemente influenciado por las nuevas lecturas de políticas sociales a través de la noción de "capital humano" (Jacinto, 2008, 2010), los diagnósticos apuntaban a "empoderar" a los desempleados formándolos como "empresarios" de sus propias trayectorias formativo-ocupacionales 9 . Uno de los problemas más obvios de este diagnóstico en un contexto de retracción del mercado laboral (como el de los noventa) es que hacía caer el peso de la responsabilidad de la situación de desempleo sobre el sujeto trabajador ${ }^{10}$, sobre sus "habilidades, calificaciones y actitudes" —o sobre la carencia de las mismas(Pérez, 2013). Así, muchas veces se critica este enfoque como voluntarista, pues deja de lado los obstáculos estructurales para el acceso a empleos "decentes" (Jacinto, 2010: 142).

En este sentido, el diagnóstico de la empleabilidad, tal y como se aplica en Argentina, se reorienta "de las necesidades de capacitación a las disposiciones hacia el empleo"11 (Jacinto, 2008). De aquí que los gobiernos de la post-convertibilidad no sólo pusieran al empleo como mecanismo central de inclusión social, en un contexto de redinamización del mercado de trabajo, sino que formatearan su intervención sobre este ámbito a partir del modelo de las "políticas activas", "ya que en principio implican una contraprestación como condición para recibir el subsidio" (Neffa, 2012) $)^{12}$.

${ }^{9}$ Aunque con más énfasis en su dimensión formal que en su dimensión práctica, el PJJHD ya planteaba sus fundamentos en torno a la idea de "empoderamiento" y de "romper con lógicas asistenciales", construyendo una lógica antropológica meritocrática y basada en el esfuerzo individual. Por esto, el estudio antes citado entiende que los objetivos se habían basado "en hipótesis explícitas o implícitas respecto de la dinámica de la pobreza y el desempleo, como funciones complejas de la demanda en el mercado de trabajo en los problemas 'actitudinales' y 'comportamentales' de las 'culturas de la pobreza'" (Andrenacci, Ikei, Mecle et al, 2006).

${ }^{10} \mathrm{El}$ problema del empleo juvenil se comprende, por un lado, a partir del desarreglo de expectativas de los jóvenes inempleables y las demandas reales del mercado de trabajo (Salvia, 2008), y por el otro, por un déficit de competencias o, en otras palabras, de capital humano y educación (Salvia, 2013).

11 "En términos específicos de políticas de empleo, se pasa de un modelo de subsidios a los desempleados a un modelo basado en la "activación", es decir, la concepción de que el beneficiario debe realizar una contraprestación (que puede ir desde un "trabajo" en el ámbito público o privado hasta un curso de formación profesional o la organización de un microemprendimiento) a cambio del monto que percibe" (Jacinto, 2010: 129)

${ }^{12}$ Si bien podemos reconocer que el PJJHD ya implicaba una política de tipo "activa", pues formalmente requería de una contraprestación de tipo "laboral" (en distintos tipos de espacios), es recién, con los nuevos programas, que esta condición se habría puesto en práctica efectivamente. De hecho, la plataforma informática del Programa Jóvenes, el establecimiento de plazos bien determinados, etc., apuntan a operativizar este estricto control de los agentes estatales (fundamentalmente, los tutores, es decir, los encargados de realizar el proceso de acompañamiento y orientación directa de los beneficiarios en el programa y sus distintos servicios) sobre la "actividad" de 
La noción de empleabilidad, como ya lo planteamos, implica desde competencias puntuales demandadas por el mercado de trabajo, hasta competencias mínimas, interaccionales y transversales para desempeñarse en la vida social (Jacinto, 2010: 126-127).

Faltos de experiencias laborales de calidad, muchos jóvenes no manejan códigos, roles y rutinas habituales en el ámbito laboral, y muchas veces son estas cuestiones las que están detrás del no acceso o la pérdida del empleo, tanto por insatisfacción del joven como del empleador. De algún modo, está presente en esta perspectiva el diagnóstico de la falta de información como uno de los obstáculos a la inserción laboral juvenil (Jacinto, 2010: 139).

En esta línea de pensamiento, lo que estas investigaciones observan es una descentralización del lugar del trabajo en la vida y en la formación identitaria de los jóvenes, a partir de una fuerte des-motivación por el trabajo y de una relación modificada de los jóvenes y la cultura del trabajo (Jacinto, 2010; Pérez, 2013). Esto se explicaría tanto por una característica propia de la generación (crisis moral, rebeldía, cultura posmoderna, no valoración del esfuerzo, etc.), como por características asociadas a su condición socioeconómica "vulnerable" y sus trayectorias familiares - hipotéticamente - atravesadas por la historia del desempleo y la asistencia social pública. En esta nueva situación fue central el criterio de la "contraprestación" para la asignación de "ayudas económicas no remunerativas" en el marco de los programas.

Por último, la categoría de empleabilidad se vuelve fundamental para entender el objeto que, a la vez, identifica y constituye este diagnóstico sobre el problema del empleo en jóvenes como campo de intervención: esta noción engloba, al mismo tiempo, las competencias técnicas necesarias para la consecución de un empleo (relativas a la capacitación ${ }^{13}$ ) y las actitudes para el trabajo, los valores culturales necesarios no sólo para conseguir sino también para mantener un empleo (relativas a la orientación y la inducción). Como podremos ver, en el discurso de los agentes estatales, estos componentes tendrán pesos relativamente desiguales en razón a su poder legitimador.

\section{El Programa}

Este programa se forma en el año 2008 a partir de la resolución ministerial 497 del mismo año, en el marco del Plan Integral para la Promoción del Empleo "Más

los beneficiarios. Veremos luego que esta característica es recuperada privilegiadamente en el discurso de los agentes para trazar fronteras políticas respecto de "Planes sociales" que precedieron al programa. Tampoco debemos olvidar que, bajo el control de organizaciones políticas y sociales y de gobiernos municipales, la dinámica del plan y sus recursos adquiría una complejidad de la cual no podemos dar cuenta aquí.

${ }^{13}$ Ya en la década anterior, la Ley de Fomento del Empleo de 1995 genera la figura de la relación de "aprendizaje", como vínculo contractual diferente al de la relación laboral (obviamente, menos estable y con derechos y obligaciones diferenciadas) como una instancia válida en el mundo del trabajo para todos aquellos que necesitaran acrecentar sus "capacidades" y "actitudes" en pos de adaptar la "oferta" a la "demanda" en el mercado de trabajo. 
y Mejor Trabajo" bajo la dependencia del MTESS de la Nación. Sin embargo, es puesto en funcionamiento a través de acuerdos territoriales con distintos municipios (en Córdoba desde el año 2010), formando una Red de Oficinas de Empleo que brindan una diversidad de servicios: apoyo a la búsqueda de empleo y a la inserción laboral, intermediación laboral y orientación a toda la población y a todos aquellos programas y planes sociales dependientes de la GECAL (Seguro de Empleo y Capacitación, Programa de Empleo Comunitario, etc.).

Como ya adelantamos, la formulación de esta política responde a una franja de población en la cual, si bien descienden los niveles de desempleo respecto de las mediciones de los años noventa, se mantienen niveles elevados en relación a las tasas de adultos (Pérez, 2010). En este sentido, y siguiendo el diagnóstico y la caracterización de entidades internacionales como la Organización Internacional del Trabajo (OIT), el programa apunta a intervenir sobre el problema de la empleabilidad.

Las Oficinas de Empleo, ubicadas en distintos puntos del territorio de la ciudad, cuentan con agentes dedicados a distintas funciones: tutores, dedicados al acompañamiento y orientación de los jóvenes en sus distintas actividades; relacionadores, dedicados al vínculo con empresas y organizaciones para la realización de "entrenamientos laborales" y a su supervisión; y orientadores, que se encargan de las tareas de coordinación de las distintas actividades propuestas desde el programa.

Los beneficiarios-destinatarios del programa son jóvenes entre 18 y 24 años de edad, sin su escolaridad formal finalizada, que se encuentren desempleados o sin un trabajo registrado legalmente. El PJMyMT cuenta con cinco líneas de acción básica: la primera (condición que los beneficiarios tienen que cumplir para el acceso al resto de las prestaciones) es el Proceso de Orientación e Inducción al mundo del trabajo (POI), una suerte de curso-taller introductorio, dictado por distintas instituciones (universidades públicas y privadas, fundaciones, ONGs, movimientos políticos, etc.), con una duración de dos meses, que consta de distintos módulos, y cuyo objetivo es, a la vez, la introducción de los jóvenes en la vida laboral, sus normas, prácticas, derechos y obligaciones, y la construcción de "proyectos formativo-ocupacionales" a partir de los cuales se desarrollarían acciones planificadas en el marco del programa ${ }^{14}$ :

se le brindará al joven elementos para la identificación de: I) sus intereses, necesidades y prioridades y su vinculación con un proyecto formativo y ocupacional; II) las particularidades de su entorno social y productivo para elegir estrategias de formación y trabajo; III) los saberes y habilidades para el trabajo que haya adquirido en distintos espacios de aprendizaje y experiencia; y Iv) estrategias adecuadas para

${ }^{14}$ Los cursos se organizan con clases de 30 beneficiarios inscriptos, cuya asistencia es un objeto de control y negociación permanente entre las partes (tutores, docentes y beneficiarios). Las clases tienen lugar tanto en espacios céntricos de la ciudad (centros de capacitación, sedes de universidades, etc.) como en los distintos puntos territoriales en los que el programa funciona, y tienen una periodicidad de tres veces por semana. Aquellos que cumplen con los criterios aceptables de asistencia (criterios definidos antes en la instancia práctica de negociación que en la formal de la "letra" del programa) cobran un beneficio económico de $\$ 450$ (equivalente según cotización oficial a U\$S 85) durante dos meses. 
planificar y desarrollar su itinerario de formación, búsqueda y acceso al empleo (Resolución MTESS 497-2008. Las cursivas son nuestras).

Una segunda línea es la Certificación de Estudios Formales (CEF), que consiste en asistencia económica para la terminación de su escolaridad en Centros de Educación para Adultos. La tercera línea es la Formación Profesional (FP), en la que se brindan distintos tipos de capacitaciones laborales a partir de convenios con Instituciones, Municipios y Sindicatos. La cuarta es un apoyo económico y técnico a la formación de micro-emprendimientos de autoempleo. Por último, los denominados Entrenamientos Laborales, que consisten en pasantías en empresas u organizaciones con una duración entre 3 y 6 meses $^{15}$.

Una particularidad del programa es su forma de asignar las prestaciones económicas: a diferencia de otros programas, sólo consiguen la prestación monetaria (variable, de acuerdo a la actividad ${ }^{16}$ ) aquellos beneficiarios asignados a servicios del programa (es decir, aquellos que realizan alguna "actividad"). Esto implica un seguimiento constante que realizan los agentes del equipo técnico a través del soporte de la plataforma informática del ministerio. Esta característica aparece de forma recurrente en los discursos de los entrevistados, pues pone en funcionamiento efectivo una de las características fundamentales de las llamadas "políticas activas de empleo": las contraprestaciones laborales (Neffa, 2012).

\section{La gestión de la empleabilidad: la visión de la burocracia}

\section{1. El diagnóstico}

Como dijimos, las formaciones estatales llegan muchas veces, a través de las políticas públicas, a establecer límites importantes para las acciones de sus ciudadanos, aunque no por esto logren fijar de manera acabada el sentido de las prácticas que, o bien promueven, o bien intentan desalentar. Como antes planteamos, la idea-fuerza del diagnóstico sobre la problemática de empleo juvenil en el marco de las políticas activas es la noción de empleabilidad. Sin embargo, la definición que muchos de estos agentes construyen sobre esta idea no se limita exclusivamente a los fundamentos teóricos de las políticas de empleo.

Con la población que nos manejamos, con jóvenes que no saben qué decir, a veces saben un montón de cosas y no las saben expresar, entonces, a veces, vos decís: 'Bueno, sí, son objetivos muy pequeños', pero sí. Porque esa es la idea, generar

${ }^{15}$ El objetivo que el equipo técnico le atribuye a esta prestación es la de la futura incorporación del joven en el puesto de trabajo en el que se desempeña la "práctica". Formalmente, una misma empresa no puede incorporar a un mismo joven en entrenamientos por más de un período, sino que debe tomarlo a través de un Programa de Inserción Laboral, que implica ya una relación de dependencia con los derechos y obligaciones establecidas por ley. Esta intención, sin embargo, pocas veces se logra.

${ }^{16}$ Para los servicios de POI, CEF y FP y el curso de autoempleo, el monto que los jóvenes reciben es de $\$ 450$ (equivalente según cotización oficial a U\$S 85 por mes de acuerdo al monto de las prestaciones para el año 2011. Para los entrenamientos es de \$1000 (equivalente a U\$S 190). 
empleabilidad, no es directamente, si hay inserción laboral bienvenida sea, de hecho hay casos, pero es difícil por una cuestión, digamos, y más que ahora estamos en un contexto macroeconómico distinto de lo que era (Agente del equipo técnico. Varón. 37 años).

Se utiliza la noción de "empleabilidad" para justificar y limitar los objetivos de esta política. En la presentación del programa a sus potenciales beneficiarios, los tutores repiten una y otra vez que el objetivo del programa "no es la inserción", y que en las oficinas de empleo no podrán "buscarles un trabajo". En cambio, la idea es "mejorar sus oportunidades" de conseguir uno, "ayudarlos a buscarlo".

No tenemos tanto esa posibilidad [la de insertarlos]. Igual a medida que yo fui, fue avanzando el año me fui encontrando con que por ahí era más a, digamos, hubo más dificultades de tipo, si queremos dar un nombre así muy de [...] más actitudinales que de capacidades técnicas. En general son chicos que, casi todos aprenden rápido, no tienen dificultad en eso, sí hay más dificultad en cuanto al hábito de trabajo y de resolución de problemas entre pares y con superiores. Eso es lo que por ahí nos trae más problemas... (Agente del equipo técnico. Varón. 24 años).

No, mirá, si bien los chicos lo que tienen es una cuestión de...cuestiones culturales o familiares, los chicos en general, no es una cuestión de capacidades, porque eso ya es en el hacer, cuando los pones al frente de una computadora, de la máquina industrial o lo que sea, no va por ese lado. Yo me refiero, el patrón general, son chicos, digamos, tímidos, poco extrovertidos, que no se animan a expresar lo que han hecho, que creen que, en ese sentido, creen que no, que todo lo que han hecho no, por más que hayan sido experiencias positivas [...] porque no tienen digamos, qué sé yo, porque en el colegio nunca le dan...una currícula, nunca le han dicho: ‘Bueno, mirá, qué es... trabajo’ (Agente del equipo técnico. Varón. 37 años).

La referencia a "cuestiones culturales" pone a las claras algunos de los componentes que empiezan a tomar un fuerte peso en la definición del problema de la empleabilidad en el trabajo cotidiano de estos agentes: las "competencias comunicacionales o básicas". No habría tantos problemas de "calificación técnica" (de hecho, casi todos manifiestan la destreza técnica de muchos de los beneficiarios), sino un déficit interaccional: la posibilidad de comunicarse con sus compañeros de trabajo, con la autoridad, e incluso la posibilidad de responder satisfactoriamente ante una entrevista de trabajo, es decir, de "vender" sus capacidades en el mercado de trabajo.

Son bastante variados. Bueno, digamos, ahí uno puede ir viendo los sectores digamos...los chicos a veces tienen incorporado que no saben hacer nada y en realidad saben hacer muchas cosas, pero es una cuestión de... que cuando uno le pregunta ¿Qué sabes hacer? Te responde lo socialmente esperable y te dicen trabajos típicos que decís bueno, tienen que saber hacer computación, pero por ahí que se yo, cocinan en su casa, por ejemplo, por ahí hay chicas que la mamá se va a trabajar, qué sé yo, y le dan de comer a todos los hermanos, y esa chica para un puesto de cocina en un restaurant... bárbaro (Agente del equipo técnico. Varón. 28 años). 
Mostrarse, venderse. No saben vender, no saben mostrarse, mucha... como vergüenza. Hay otros casos ¿no? Pero yo te digo como la generalidad. A la hora de presentarse, cuando vos le conseguís el trabajo, estamos teniendo un montón de dificultades, digamos, con el hábito de la responsabilidad (Agente del equipo técnico. Varón. 37 años) ${ }^{17}$.

A partir de una evaluación de las trayectorias familiares y laborales vulnerables e inestables de estos jóvenes, además de la vivencia de una escolaridad de baja inten$\operatorname{sidad}^{18}$, muchos de los agentes estatales entienden que los jóvenes no han adquirido los valores culturales necesarios para conseguir y mantener una ocupación, como la "puntualidad", la "asiduidad", el "respeto por la jerarquía" y la "propensión a internalizar pautas" (Pérez, 2013).

En general sí te puedo decir que hay cuestiones del hábito del trabajo que hacen bien difícil la cuestión, cuestiones de relación interna, de aprender a convivir con la autoridad, por ejemplo, o aprender cuándo es, cuándo puedo yo acatar una orden sin que esa orden me destruya mi subjetividad, porque está o el joven que confronta todo el tiempo o el joven que [acepta las órdenes y funciona bien] (Agente del equipo técnico. Mujer. 27 años. Las palabras entre corchetes son del autor) ${ }^{19}$.

Esto se ve fuertemente reflejado en la preocupación de la mayoría de los agentes por las ausencias en los espacios de trabajo cuando los beneficiarios realizan "entrenamientos". Este es uno de los problemas más frecuentes y que más disruptivos resultan en la apreciación de los empleadores, dado que es tomado como un claro indicador de desinterés e irresponsabilidad:

El eje es empleabilidad, y empleabilidad tiene que ver con incorporar hábitos, con incorporar aprendizaje [...] Hábitos de cumplir horarios, hábitos de saber que si te enfermas tenés que avisar, hábitos de, pero también el habito de que se tiene que respetar un horario en la empresa que tiene que haber un acuerdo que vos firmás que tiene que respetar la empresa, que tiene que haber una cobertura médica y un seguro, digo, no son solamente obligaciones del pibe aprender sino también entender que esto que vieron en el POI que tiene que ver con derecho laboral es real en una empresa siempre que se relacione ¿no? Le permitirá, entonces, si todo sale bien, lograr ahí un buen trabajo en blanco...o poder aspirar a un trabajo mejor del que han tenido (Agente del equipo técnico. Varón. 25 años).

${ }^{17}$ En una investigación sobre este campo en España, Antonio Martínez López muestra las consecuencias de esta manera de encarar la orientación para los beneficiarios: "El usuario debe de dejar de creer que se le va a buscar un empleo, debe de aprender a venderse a sí mismo, y en definitiva tiene que asumir toda responsabilidad en el proceso. Como es dicho común entre los orientadores: 'tiene que currárselo'. Si fracasa, será también responsabilidad suya por haber demostrado una incompetencia como empresario de sí mismo, como vendedor de su imagen laboral personal" (Martínez López, 2009: 161)

${ }^{18}$ Para un desarrollo más profundo de esta idea, ver Kessler (2002).

${ }^{19}$ Esta distinción adquiere bastante relevancia en algunos discursos, aunque nunca llega a explicitarse como una separación tajante entre casos "problemáticos" y "positivos" (escisión que sí pudimos encontrar en los discursos de docentes de escuelas a las que asisten algunos de estos jóvenes, aunque no nos dediquemos a ello en el presente trabajo). 
Lo que pasa es que nosotros al tener la primera instancia de capacitación, del POI, donde los chicos tienen que cumplir horarios, tienen que asistir, todo, es como que vuelven a estar dentro de un margen institucional que tienen que cumplir horarios, cumplir asistencias, entonces, cuando uno ya los deriva a la práctica, si bien sí faltan, a veces no avisan, sobre todo en las prácticas, pero no es la gran mayoría. Están como reglamentados, que tienen que avisar, que tienen que respetar a la persona que tienen en la empresa, que no tienen que faltar... (Agente del equipo técnico. Mujer. 26 años).

En esta evaluación, el problema de la empleabilidad pasa de ser una noción vinculada a la calificación laboral y a las competencias comunicacionales a ser un problema moral: el viraje ya mencionado de las calificaciones a las disposiciones (Pérez, 2013). Este conjunto de valores relativos a la "presentación de sí", a la "puntualidad", la "responsabilidad", etc., tienen un asidero fundamentalmente subjetivo, y tienen como centro articulador el valor del "esfuerzo".

Uno los ve, como que los ámbitos familiares, o la postura que hay en los valores tradicionales, si se puede decir, o los contextos familiares, esas nuevas formas de familia que hay, es como que el joven no está preparado para esa sociedad; o vienen muchos jóvenes de generaciones de desempleo estructural, o sea, ni los abuelos trabajaban, ni los padres. Entonces la única cultura, o el mundo del trabajo, como no son valores aprendidos, entonces hay jóvenes que no han visto ni laburar a sus viejos, entonces [...] si vos no ves un ritmo de vida que de lunes a viernes tu viejo se va en el auto o en el colectivo a laburar, o en la bici [...] es lógico cuando, digas, si vos tenés que ir a laburar digas: ‘¿Por qué?, ¿Qué es eso?' (Agente del equipo técnico. Varón. 37 años).

Como ya lo planteamos anteriormente, parte de la causalidad del déficit recae (en el discurso de los agentes), sobre una trayectoria familiar entre cuyas imágenes cotidianas no aparece la del padre-trabajador-proveedor que parte, día a día, a realizar su trabajo. Se construiría entonces un problema de socialización laboral deficitaria: años de desempleo masivo (y también, como veremos, de "política asistencialista") habrían generado una enorme grieta en lo que podemos denominar como el horizonte valorativo de la "cultura del trabajo".

Este horizonte de significación centrado en el esfuerzo es fundamental para comprender la manera en la que estos agentes definen su propia concepción de las "políticas activas". La "contraprestación" tiene, en este marco, el sentido de una práctica, a la vez, habitual y formadora de hábitos, formadora de disposiciones para el trabajo. Esto se identifica como una necesidad fuerte en el contexto de las intervenciones sobre la empleabilidad, dado que en las distintas instancias del programa aparece como un obstáculo.

Si, si porque uno les dice: 'El POI el obligatorio, vos cuando firmaste el convenio te comprometiste a hacer el POI y es motivo de desvinculación', y el joven: 'Bueno, sí, sí', y después lo llamas por un POI, lo llamas para el otro, si es que lo va pateando y no quiere. Entonces bueno, llega un punto que por más que [...] se cae (Agente del equipo técnico. Mujer. 29 años). 
Por otra parte, este valor es uno de los ejes que se trabajan en el primero de los servicios del programa: el POI. Por lo que han declarado varios tutores, pero también algunos docentes a cargo de estos espacios que hemos entrevistado, los contenidos de este curso (aunque no estén totalmente estructurados en esta dirección) adquieren ciertos visos de "autoayuda", de trabajo de introspección, de descubrir las propias competencias y "planificar" la formación como un proyecto. En este marco, la posibilidad de hacerlo pasa en gran medida por afirmar la validez de los criterios de "mérito" y del "esfuerzo personal" como elementos de distinción legítimos ${ }^{20}$.

Hay chicos que vienen con un entusiasmo, porque como que en el POI se arma toda la historia de, de esto de, que también como tutores hemos sido críticos muchas veces de lo que es el taller del POI; de la idea de esto de la voluntad, del mérito, del esfuerzo personal. Y entonces el joven sale muy entusiasmado, que va a venir al programa, va a conseguir una beca, una práctica laboral en una empresa, se va a insertar, y muchas veces no sucede esto. (Agente del equipo técnico. Varón. 32 años).

En su práctica y su discurso, la agencia estatal impone ciertas categorías y clasificaciones de realidad en términos de subjetivación de los beneficiarios. El funcionamiento práctico de la noción de empleabilidad se entrelaza con el diagnóstico de la problemática en términos culturales, $\mathrm{y}$, en este sentido, actualiza la perspectiva analítica de la dimensión formal del PJMYMT. El foco en la formación de conducta, hábitos y formas de presentarse e interactuar, explicita y enfatiza elementos programáticos, recuperando la terminología técnica del programa y disponiendo sentidos sobre el trabajo y la política sólo comprensibles en su contexto de aplicación.

\subsection{La política activa y el "trabajo artesanal"}

El sentido de la política activa de empleo como formulación teórica de las resoluciones ministeriales y de los informes de los organismos internacionales como la OIT o el Banco Interamericano del Desarrollo (BID), se actualizan en el marco de las prácticas de los agentes estatales de maneras singulares. Como ya adelantamos, la "contraprestación" requerida que define este modelo de políticas, constituye una práctica de modelación conductual, de intervención sobre un problema situado en torno a "cuestiones culturales".

Y empieza a cambiar una lógica fundamental del programa, si bien ya habíamos tenido alguna lógica de los programas que veníamos desarrollando hasta ese momento, si bien habíamos tenido una experiencia previa con los jefes y jefas de hogar, que cuando se pasan al seguro de capacitación y empleo, se comienza realmente a... a tener sus frutos en este programa y que es que el joven va a cobrar una beca económica, pero en función a su esfuerzo, en función al cumplimiento de las acciones ¿no? (Funcionaria del Ministerio de Trabajo. Mujer. 42 años)

${ }^{20}$ Como sostiene Didier Fassin, "No cabe duda de que, para los pobres, como para los inmigrantes, la línea divisoria de la legitimidad social pasa entre los que tienen mérito y los que no lo tienen" (2003: 61). 
Esta lógica no aparece solamente como una condición impuesta para la consecución de un beneficio económico, sino como un criterio legitimante para la práctica y para el programa como política. En relación a este criterio y al tipo de diagnóstico construido en torno a la empleabilidad, la tarea propia de tutores, orientadores y relacionadores se define, en términos generales, como "artesanal".

Se hace difícil, digamos, es un trabajo bastante artesanal la inserción laboral de este tipo de jóvenes, no llegamos a cumplir las metas cuantitativas, entonces se hace, es difícil, porque si no podemos responder todavía a demandas puntuales de marzo, abril, a esta altura del año, estamos ya en septiembre, es complicado (Agente del equipo técnico. Varón. 37 años).

Por otra parte, los agentes comprenden su posición como atrapada entre intereses políticos diferenciales. Estos intereses corren paralelos o independientes a los objetivos del programa, que ellos definen en términos a-políticos (aumentar la empleabilidad), y se establecen por las pugnas propias de la arena política.

Es como complicado coordinar a personas, digamos, que no cobran, yo hace un año, por ejemplo, que no cobro, es como complicado. Y también porque desde la Municipalidad y desde la gerencia, y los objetivos son como diferentes, entonces también tratar de unir un poco, y tener esa lógica del programa vigente [...] Porque, claro, la Municipalidad lo que más le interesa, sobre todo, es la cantidad de jóvenes en prestaciones, no le interesa tanto la cantidad de jóvenes inscriptos dentro del programa que, sí es lo que le interesa a la gerencia ¿Sí? O sea, a nosotros nos habían establecido para este año 5000 jóvenes inscriptos como un objetivo prioritario desde la gerencia, del Ministerio de Trabajo. En cambio, la Municipalidad, en donde está haciendo foco es en la capacitación, sacando 24 cursos territoriales, en el territorio de la Oficina de Empleo, y lo que son los entrenamientos laborales. Hacen mucho más foco en eso. Entonces tenemos una disyuntiva, de decir, bueno, tenemos que tener muchos chicos en las inscripciones y también una vez que terminen y se inscriban todos empezar la prestación entonces... es mucho más dinámico. Coordinar esas dos visiones, digamos, es también difícil. Es difícil, y bueno, también tenemos esta paradoja, digamos, de ideologías políticas que también, nosotros también sabemos que tratamos jóvenes que sean lo más apolítico posible. Si, es muy importante para nosotros porque a nosotros lo único que nos importa es que los jóvenes aumenten su empleabilidad. Es el objetivo primordial del programa. Pero bueno, teniendo también esta disputa entre que, bueno, la Municipalidad es radical y la gerencia... kirchenirsta, también se complica un poquito con eso (Agente del equipo técnico. Mujer. 26 años).

Aquí no sólo importa la cuestión de las ideologías políticas particulares que participan de la vida del programa, sino cómo estas se asocian a una lógica de funcionamiento "burocrática", centrada en lo "cuantitativo" y en el "protocolo": ante esta racionalidad, los agentes oponen su actividad personalizada, cualitativa, artesanal.

Por otra parte, la dimensión de los intereses "económicos" aparece inicialmente como un elemento de "desconfianza" (de los agentes estatales para con los beneficiarios). Ante este "interés" se interpone el des-interés que tiñe la interpretación de 
estos agentes respecto de las prácticas de los jóvenes en el programa. Uno de los tutores, en particular, nos planteaba que

No es una cuestión económica, a eso voy. Por ahí el programa tiene como una cuestión, que está bien, está bueno el incentivo, aparte el hecho de decir: 'bueno, incorporo el hábito del trabajo', sí, pero, digo, se incorporan otras cosas, por el hecho de que el chico va a ir a un entrenamiento, genera [...] a lo que es el trabajo, las reglas, digamos, hay que como hacer un, o por lo menos frente a ciertos casos hay que hacer una mirada un poco más crítica y evaluativa sobre ese joven sino es probable que fracase (Agente del equipo técnico. Varón. 28 años).

Esto no implica un olvido de las estructuras económicas como condicionantes de las prácticas de los jóvenes. La mención a sus condiciones "vulnerables" es una constante en el discurso de los agentes. Sin embargo, mientras que cuando hablan de la trayectoria de los jóvenes y su adaptación a la lógica de los "planes"21 prima una evaluación en términos de instrumentalidad ("son sinceros y te dicen que vienen por la plata"), al evaluar el paso de los beneficiarios por el programa aparece enfatizada la motivación moral y la construcción del trabajo como una cuestión fundamentalmente vinculada a los "valores" y los "hábitos". En la práctica cotidiana, los agentes encaran permanentemente una reversión de la lógica económica por una lógica moral: aquellas veces que los jóvenes llegan a la oficina preguntando por la "beca" o el "plan", los tutores corrigen marcando la denominación correcta: "el programa".

Otro criterio de evaluación que aparece en el discurso de los agentes, y que presenta una lógica homóloga a la distinción entre el interés y el des-interés, es la diferenciación entre "necesidad" y "vocación" para realizar alguna prestación. Lo que este razonamiento indica es que no siempre la necesidad económica lleva a un buen resultado en los entrenamientos laborales, mientras que la vocación (por definición, un acto liberado de necesidad) ayuda a un mayor aprovechamiento de la misma. La necesidad funciona como elemento que colabora con la urgencia y lleva a los jóvenes a centrar su visión en el presente y a limitar su capacidad para planificar ${ }^{22}$. Esta clasificación permite a algunos de estos agentes distinguir a los beneficiarios realmente interesados, que serían aquellos que, según su experiencia, mejor se desempeñarán y más aprovecharán los servicios del programa.

En relación a un campo de intervención definido como "competencias subjetivas", la actividad de los agentes del programa debe ajustarse a criterios de "orientación" especializada, focalizada, teniendo en cuenta las particularidades de cada

${ }^{21}$ Con esta denominación coloquial suele hacerse referencia al amplio y diverso espectro de políticas sociales, laborales, de seguridad social, etc. Si bien su denominación es vaga, su sentido quedó, en alguna medida, atado al contexto situacional de la década de los noventa y al modelo estatal y económico de la convertibilidad.

${ }^{22}$ Esta idea pone de manifiesto un modelo ideal de beneficiario vinculado a un manejo del tiempo propio de la cosmovisión de las clases medias, su inversión de tiempo y trabajo a largo plazo en la acumulación de credenciales educativas y de su valorización en el mercado de trabajo. 
trayectoria, de cada individuo ${ }^{23}$. Por esto, la acción de la "entrevista" resulta tan relevante para construir un conocimiento acabado de los intereses, actitudes y habilidades de los jóvenes, además de la información con la que se construye el "perfil" 24 una vez completado el POI. Muchos de estos agentes definen esta relación como "personalizada" 25 , oponiéndola a la clásica mediación burocrática de las relaciones entre los ciudadanos y el Estado ${ }^{26}$, de la frialdad de las listas y las planillas, de la política instrumental. Tal como sostiene Didier Fassin, "la administración se humaniza en esta individualización de los tratamientos" (2003: 60).

En el marco de esta personalización, los agentes construyen lazos de "confianza", llevan sus propios registros por fuera de los límites impuestos por la "plataforma informática", se salen del protocolo de acción. Construyen una relación "cálida", de orientación pero también de contención, como contrapartida lógica de un problema del empleo pensado en términos de "subjetividad".

Entramos en código y yo les explico siempre todo y trato de que ellos puedan ir construyendo esta confianza necesaria, porque es, cuando vos llegas a una oficina, a mi me ha pasado de hacer, de estar sin trabajo y he pasado de tener que hacer entrevistas que te preguntan hasta el color de la bombacha ¿viste? Y es fuerte. Entonces yo como que trato de construir ese vinculo de confianza y de calidez para, para que no sea tan así ¿no? Para que no se sientan invadidos ¿viste que vos te sentís?, le conté mi vida a alguien que no conozco, o sea. Entonces bueno, como que voy trabajando mucho eso y trato de que ellos se sientan cómodos y que vengan a la oficina, y cuando vienen, bueno, tomate un mate, hablamos (Agente del equipo técnico. Mujer. 27 años).

Tal como lo entienden Cortés y Kessler, algunos de estos sentidos se enmarcan en un proceso político más estructural:

${ }^{23}$ Tal como lo plantea Antonio Martínez López, “intentando cumplir y dar sentido a un trabajo que consiste en un mandato hasta cierto punto imposible de realizar (mejorar el ajuste entre la oferta y la demanda de trabajo), los orientadores laborales contribuyen, junto con otras instancias y operaciones, al proceso de individualización de la oferta de trabajo que rige en el mundo de las relaciones laborales en el escenario de la flexibilidad y el modo de producción postfordista donde estaríamos hoy instalados (Martínez Lopez, 2009: 161).

${ }^{24}$ El denominado "perfil" es una suerte de registro de información (no siempre sistematizada) que se construye a partir de las entrevistas (de incorporación, de seguimiento, etc.) realizadas a los beneficarios, como así también a partir de los informes de los docentes luego de transcurrido el POI. Incluye datos generales referidos a lo laboral (experiencias, gustos, pretensiones), como así también datos informales que aportan información valiosa para la dinámica cotidiana de las actividades del programa (si posee motos, cómo es su carácter, si tiene hijos o adultos a su cargo, etc.).

${ }^{25}$ Esta definición aparece más en términos de "ideal" que de funcionamiento de hecho. En realidad, los agentes reconocen que la masividad del programa los imposibilita para llevar adelante este seguimiento personal, razón por la cual reconocen que las comunidades pequeñas son lugares aptos para un óptimo funcionamiento del programa: espacios en donde todos se conocen, en donde se puede ir "puerta por puerta", etc.

${ }^{26}$ Como luego veremos, esta imagen se vincula a las prácticas de los modelos anteriores de política social, es decir, al "asistencialismo". 
El dilema central era la asistencia: si era posible prescindir de ella, había que dotarla de un cariz diferenciador para lo cual, muestra L. Perelmiter, se practicó una estrategia ideológica e institucional. Se identificó a los noventa con una visión tecnocrática a la que la Ministra [de Desarrollo Social de la Nación], hermana de Néstor Kirchner, opuso la óptica de su profesión, el trabajo social, colocando a la "distancia" como problema político entrañando frialdad, centralismo y un saber teórico contra lo cual se planteaba "bajar al territorio", revalorizando los rasgos menos apreciados académicamente de dicha disciplina, como lo son la cercanía y el compromiso afectivo (Cortés y Kessler, 2013: 253-254).

Si bien la cita hace referencia a otra jurisdicción institucional y ministerial, muestra de alguna manera la misma lógica que creemos estar identificando en el discurso de algunos de estos agentes: una lógica, a la vez, ideológica e institucional, política y moral.

Este seguimiento minucioso se complementa con la necesidad de control permanente para hacer efectiva la tarea de formación de nuevos hábitos y valores para el trabajo (controlar la asistencia, llamar y convocar en caso de ausencia en el espacio de trabajo, acompañar el proceso de inserción, etc.), pero también nuevas "aspiraciones" (a un empleo digno, "en blanco"27, etc.). En este sentido, control, personalización y disciplina ${ }^{28}$ van de la mano.

Por otra parte, es recurrente en las entrevistas la mención del carácter de "técnicos" o "profesionales de la cuestión social" de los agentes para definir el equipo de trabajo. En cierta forma, los agentes trasladan este tipo de selección por credenciales educativas a un cierto reconocimiento en torno a su "compromiso social" ${ }^{29}$, necesario para soportar las condiciones laborales a las que están expuestos. Desde distintos lugares, esta idea es recuperada: desde el ministerio, marcando una discontinuidad con el "amiguismo" como forma de ocupar cargos en el Estado. Desde el equipo técnico, como una manera de legitimarse ${ }^{30}$ frente a los "empleados de planta" (empleados registrados con plenos derechos) municipales ${ }^{31}$.

${ }^{27}$ Forma coloquial de referir al empleo legalmente registrado, con las protecciones de la seguridad social.

${ }^{28}$ Corrigan y Sayer definen la noción de disciplina de esta manera, recurriendo a autores clásicos: "De lo que están hablando Marx y Durkheim es del intento de construir las expectativas, de la internalización de las normas burguesas como constitutivas de la personalidad" (Corrigan y Sayer, 2007: 79).

${ }^{29}$ Nótese que la referencia es lo "social" y no lo "político".

${ }^{30}$ Shore pone como ejemplo de la capacidad legitimante de lo técnico la imposición del Euro como moneda en las distintas naciones de Europa: “¿Cómo logró tener éxito la política? No fue por medio de la consolidación de un apoyo popular sino de una evasión total del debate público y del rechazo de cualquier posibilidad de disenso. La UEM fue presentada no como un asunto político o constitucional que requería un mandato democrático, sino como un asunto técnico y económico" (Shore, 2010: 40). En cierta forma, oponerse a un designio "técnico" implicaría oponerse a lo dictado por la "razón" (técnica), lo cual significa exponerse a una gran pérdida de legitimidad.

${ }^{31} \mathrm{Su}$ condición de contratación es la de "monotributistas", locatarios de obra para el Estado municipal. A esto debe sumarse una demora de entre 10 y 13 meses para el cobro de sus "honorarios", período en el que no sólo deben abonar el pago del monotributo, sino que además son 
Y que bueno, y hay muchas cosas más que yo veo como que...es positivo digamos, el hecho de que pidan equipo, gente, pre profesional o profesional para que conforme el equipo técnico también es sumamente bueno, le da un valor agregado bárbaro de... lo quita del punterismo y es positivo eso, sumamente positivo (Agente del equipo técnico. Varón. 28 años).

La autocomprensión de la tarea de los agentes estatales en términos de un trabajo artesanal y de una atención y orientación personalizada forma parte de la construcción de la autoridad moral de esta agencia estatal para intervenir, definiendo la forma especificamente legítima de esta intervención: formativa, técnica, a-política, personalizada, orientadora, cálida. En este punto se entrecruzan los sentidos que los agentes estatales imprimen sobre su práctica, sobre el programa, sobre sus servicios y sobre el empleo juvenil, por un lado, y los sentidos sobre su propio lugar en el mundo del empleo estatal y el campo burocrático, por otro.

\subsection{Diferencia entre las políticas activas y el "asistencialismo" o políticas pasivas}

La definición del problema en términos de empleabilidad, la comprensión de la propia actividad como una acción "personalizada y artesanal", de "orientación", permite comprender el énfasis con el cual los agentes trazan fronteras de diferenciación entre este programa y otras políticas sociales.

Una primera distinción es con respecto a otras políticas de empleo, como el programa provincial Plan Primer Paso (PPP), que es una reedición del plan lanzado bajo el mismo nombre, en la primera gestión del actual gobernador, en el año 1999. Este cuenta exclusivamente con el servicio de pasantías, aunque sin las funciones de orientación y acompañamiento que existen en el PJMYMT. Dado que las deficiencias laborales de los jóvenes se definen aquí como "subjetivas", no contar con este servicio significa, para estos agentes, dejar al joven, de por sí vulnerable, a la deriva.

Por otra parte, y como ya planteamos, el discurso de los agentes estatales muestra un esfuerzo por construir marcadas diferencias entre las políticas activas, como el PJMYMT, y las políticas asistenciales de los noventa. Estas diferencias se evidencian sobre todo en los discursos de funcionarios ministeriales, en general, más alineados con el discurso del gobierno nacional.

Lo que busca este programa y el Seguro de Capacitación y Empleo, con una experiencia previa con el Seguro de Capacitación y Empleo, era cambiar esta lógica y realmente que los beneficiarios, eh.. o las poblaciones destinatarias, eh... en realidad lo que busca es que sea la actividad que se hace que le sume a su competencia a su empleabilidad más que el beneficio económico. Pero bueno, es todo un cambio de cultura que es todo un proceso de largo tiempo. Entonces el programa Jefes de Hogar en realidad... el programa Jefes de Hogar en realidad... ay perdón, el

objeto de amenazas de rescisión de contrato sin ningún tipo de resarcimiento ante el menor atisbo de protesta. Ante un conflicto por el no cobro de haberes durante el primer año de funcionamiento del programa, los agentes cuentan haber sido reprendidos por algunos de los funcionarios ministeriales por su "falta de compromiso" con la tarea. 
Programa Jóvenes con Más y Mejor Trabajo, entonces, el joven tiene la posibilidad de entrar en... yo siempre cuando lo tengo que definir en un palabra al... digo, es una gran posibilidad ¿no? Que dependerá del esfuerzo de ellos de tomarla o dejarlo (Funcionaria del Ministerio de Trabajo. Mujer. 42 años).

Hasta la crisis y se tomó una medida mucho más asistencialista con el Plan Jefes de Hogar garantizando un ingreso, una ayuda económica no remunerativa mínima a todos los desocupados, o a todos los que se pudieron inscribir en tal tiempo, porque también hubo una limitación de tiempo, y el que quedaba desocupado después... o el que no accedió en ese tiempo a inscribirse, tampoco pudo, accedió después. Pero fue una medida de crisis, de urgencia en función de lo que estaba sucediendo, digamos, el contexto social, político, institucional, más que una política de empleo, ¿ah? [...] Que hoy son políticas activas de empleo donde el sujeto, el participante de un programa tiene que buscar activamente empleo, digamos, activamente empleo con ayudas, con recursos, se acerca a las oficinas de empleo, o participa de distintos programas, pero en la medida que hace [levanta la voz] alguna actividad de mejora de la empleabilidad va a percibir ayudas económicas, incentivos o premios, va a cobrar más si hace más (Funcionaria del Ministerio de Trabajo. Mujer. 50 años).

También aparecen estas diferenciaciones entre los agentes del equipo técnico, aunque sin identificarse de lleno con el discurso y la defensa política de la actual gestión del gobierno nacional, como es el caso de algunos de los funcionarios ministeriales.

Hay empresas que han trabajado con PPP ${ }^{32}$, por ejemplo. No, no todas pero vos encontrás empresas que han trabajado con el PPP. Tenés empresas que les ha ido bien con el PPP, tenés empresas que les ha ido mal PPP. Para mí estamos, digo, estamos en paradigmas más diferentes. Digo, PPP era bien neoliberal. Vos ante el mercado. Solo. Vos, vos, vos conseguís tu laburo ¿bien? Si el mercado de laburo te rechaza bue... Listo. No pudiste completar el formulario. Chau. Pero eso es una lucha uno contra uno, que podía tener éxito o no, que después no tenía un seguimiento. En este sentido creo que hay toda una visión mucho más compleja, que la dejamos muy en claro cuando hablamos con el empresario. La diferencia entre el PPP y este programa y lo que nosotros entendemos se tiene como beneficios y... y la pregunta era ¿Qué te pide? ¿Qué dan? (Agente del equipo técnico. Varón. 25 años).

Así, desde la perspectiva de estos agentes, mientras las políticas asistenciales destruían la "cultura del trabajo" y amenazaban con producir una "generación perdida", las políticas activas intentan reconstruir este entramado de prácticas y valores, recuperando el esfuerzo y la "actividad" como criterio, a la vez, legitimante y moralizante.

${ }^{32}$ El Programa Primer Paso (PPP) forma parte del paradigma de políticas activas, aunque tuvo comienzo en un contexto muy diferente del actual (1998), y bajo la jurisdicción del Estado provincial. 


\section{Palabras finales: legitimidad política y cultura del trabajo}

Algunas palabras aclaratorias se hacen necesarias antes del cierre de este texto. El investigador, a partir de una serie de operaciones epistemológicas, inmerso en una temporalidad (la de la investigación) y una lógica (teórica) distinta de la del actor lego, construye una continuidad, por demás, contingente. Lo que aquí analizamos como rasgos generales del discurso de los agentes estatales no implica el desconocimiento de algunos desacuerdos, conflictos y tensiones entre los integrantes del "equipo técnico", ni algunas contradicciones algo más importantes entre ellos y los funcionarios del ministerio.

En términos generales, y habiendo hecho esta aclaración, consideramos que los sentidos habilitados desde el programa han funcionado de manera eficaz en la fijación de los límites de posibilidad de intervención y significación en el marco del diagnóstico y el diseño de la política en términos de empleabilidad. No está de más decir que esta eficacia simbólica es reforzada e impuesta por la violencia ejercida sobre este equipo técnico a partir de la precariedad de las condiciones laborales en las que se desempeñan. De esta manera, no sólo los sentidos, sino que fundamentalmente las condiciones objetivas son diferentes y desiguales entre las distintas instancias y niveles de esta compleja formación estatal. Un análisis más exhaustivo en este sentido ameritaría un proceso de investigación en sí mismo.

Nuestro trabajo se centró en el análisis de las prácticas y representaciones de agentes estatales del PJMYMT en la medida en que formaban parte activa y fundamental de lo que denominamos la "cultura del trabajo" en jóvenes de sectores populares. Esto nos llevó a recuperar herramientas conceptuales que a) nos permitiesen asir teóricamente fenómenos que sucedían por fuera del proceso de trabajo —en sentido restringido - y b) dieran lugar a la recuperación de la importancia fundamental para nuestro análisis del momento de la puesta en práctica de la política laboral.

A partir de esta reconstrucción, pusimos de manifiesto el carácter procesual de la regulación hegemónica de los sentidos sobre el trabajo (en el marco de la política laboral), a lo largo de toda una serie de actores e instancias que involucran este programa, y que van desde la letra formal del diseño de la política, pasando por las reformulaciones discursivas y prácticas cotidianas en las distintas instancias de agentes estatales (ministeriales, del equipo técnico, etc.), hasta incluso los momentos de negociación y apropiación diferencial de sentidos en las interacciones entre agentes y beneficiarios del PJMYMT (aunque esta última instancia haya quedado fuera del análisis aquí presentado ${ }^{33}$ ). De esta manera, intentamos reflejar una serie

${ }^{33}$ Esto no quiere decir que quede por fuera del análisis total de la investigación. En una serie de publicaciones en prensa, me dedico a trabajar sobre estas apropiaciones y negociaciones de sentidos por parte de los mismos jóvenes insertos en el programa. Por la primera presentación teórica de la noción de "cultura del trabajo" que realizamos en este artículo se establece que la misma es una configuración cultural de la cual participan agentes en distintas posiciones y con recursos diferenciales. Por cuestiones de espacio, me interesaba aquí trabajar en profundidad la visión que, respecto del problema de la empleabilidad, construían un conjunto de agentes que encarnan y forman parte de una formación estatal concreta, y que desarrollan su visión desde la especificidad de su lugar. 
de movilidades, reinterpretaciones, incorporaciones de elementos, significaciones y tradiciones, en un proceso que se ubica en un horizonte común (aunque no por ello exento de marchas y contramarchas, conflictos y regulaciones) de significación sobre los sentidos, los derechos y las obligaciones en torno al trabajo.

Preguntándonos cómo intervenían estas formaciones estatales en la regulación de prácticas y hábitos laborales, reconstruimos una configuración de la cultura del trabajo que se ubica, de alguna manera, en el centro de dos construcciones paralelas e interdependientes: a) la de la autoridad moral estatal, y b) la de los criterios de valorización social que se aplican a los beneficiarios de este programa. Tal como mostramos, la definición del problema del empleo juvenil en términos culturales (empleabilidad) atribuye a los beneficiarios una serie de carencias subjetivas (incorporación y cumplimiento de normas, formas de comportarse, de hablar, etc.). En relación a esto, la definición de la tarea de los agentes en términos de orientación, formación, desinterés ${ }^{34} \mathrm{y}$ acompañamiento personalizado está fuertemente vinculada con la intervención para la incorporación de hábitos de autogestión, autorregulación y disciplinamiento por parte de los jóvenes. Por último, el uso de la figura de la activación como oposición a la tendencia en las políticas sociales asistencialistas precedentes (formadoras de pasividad), tiene su correlato en la afirmación de los valores de voluntad, esfuerzo y mérito para los beneficiarios, como criterios válidos de diferenciación respecto de la población asistencializada, rodeada de valoraciones estigmatizantes y sospechas sobre la dignidad de su derecho a las prestaciones estatales.

De esta manera, marcamos aproximaciones y puntos de ingreso a una configuración que, como red de agentes, instituciones y discursos dispuestos en torno al trabajo como valor, se constituye como marco discursivo común, desde el cual se ponen en funcionamiento, pero también se constituyen, reproducen, reordenan y consolidan una serie de recursos simbólicos que definen un punto de intersección entre la legitimidad estatal (de la institución, pero también de sus trabajadores) y la legitimidad de los jóvenes de sectores populares (desarrollada en profundidad en próximos escritos).

${ }^{34}$ La antropología abunda en discusiones clásicas sobre la implicancia de los actos “desinteresados". Como plantea Marcel Mauss (2009: 150), en realidad el "interés" que se pone en juego en algunas de estas estructuras de relaciones es un interés no-económico (o no-exclusivamente-económico, en el sentido que le otorga la economía política moderna al término) sino simbólico, es decir, por el acuñamiento de honor y por la "eficacia mágica" que el mismo conlleva (Mauss, 2009: 224). En una clave de lectura afín, Pierre Bourdieu muestra cómo el desinterés económico está vinculado a la inversión puesta en un campo o una estructura de relaciones cuyas reglas de juego hagan i-legítima la búsqueda utilitarista de beneficio económico, como por ejemplo, el campo artístico (Bourdieu, 1997) pero también, en determinadas configuraciones históricas, podríamos pensar en el campo político. Esta hipótesis se vuelve aún más relevante teniendo en cuenta el peso de la lectura "moral" de la crisis política del país en el año 2001 y las reformulaciones que esta lectura tuvo en el período posterior. 


\section{Referencias bibliográficas}

ANDRENACCI, Luciano; IKEI, Lidia; MECLE, Elina; et al

2006 "La Argentina de pie y en paz: acerca del Plan Jefes y Jefas de Hogar Desocupados y del modelo de política social de la Argentina contemporánea”, en L. Andrenacci (Comp.), Problemas de política social en la Argentina Contemporánea. Buenos Aires: Prometeo-UNGS, 181-211.

BASUALDO, Eduardo

2009 "Evolución de la economía argentina en el marco de las transformaciones de la economía internacional de las últimas décadas" en M. E. Basualdo y E. Arceo (Comps.). Los condicionantes de la crisis en América Latina. Buenos Aires: CLACSO.

BOURDIEU, Pierre

1997 ¿Es posible un acto desinteresado?” en Razones prácticas. Sobre la teoría de la acción. Barcelona: Anagrama, 139-158.

CASTEL, Robert

2000 La metamorfosis de la cuestión social. Una crónica del salariado. Buenos Aires: Paidós.

COHEN, Stanley

2002 Folk Devils and Moral Panics. The creation of the Mods and Rockers. Nueva York: Routledge.

CORRIGAN, Philip; SAYER, Derek

2007 "El gran arco. La formación del Estado inglés como revolución cultural” en M. Lagos y P. Callas (Comps.). Antropología del Estado. Dominación y prácticas contestatarias en América Latina. La Paz: INUH/PNUD, 39-116.

CORTÉS, Rosalía; KESSLER, Gabriel

2013 "Políticas, ideas y expertos en la cuestión social de la Argentina democrática (19832012)". Revista de Indias. 73(257): 239-264.

DURKHEIM, Emile

1985 La división del trabajo social. Barcelona: Planeta Agostini.

DURKHEIM, Emile

2003 Lecciones de sociología. Física de las costumbres y del Derecho y otros escritos sobre el individualismo, los intelectuales y la democracia. Buenos Aires: Miño y Dávila.

FASSIN, Didier

2003 "Gobernar por los cuerpos, políticas de reconocimiento hacia los pobres y los inmigrantes en Francia”. Cuadernos de Antropología Social. 17: 49-78.

GARCÍA RAGGIO, Ana María

1998 "Transitando por los márgenes. Las transformaciones del trabajo y el debilitamiento de la ciudadanía” en E. De Ípola (Comp.), La crisis del lazo social. Durkheim, 100 años después. Buenos Aires: Eudeba, 9-33. 
GRIMSON, Alejandro

2011 Los límites de la cultura. Crítica de las teorías de la identidad. Buenos Aires: Siglo XXI.

GUADAMARRA OLIVERA, Rocío

2000 "La cultura laboral", en E. De la Garza Toledo, Enrique (Dir.). Tratado latinoamericano de Sociología del Trabajo. México DF: FCE. 213-244.

HOGGART, Richard

2013 La cultura obrera en la sociedad de masas. Buenos Aires: Siglo XXI.

JACINTO, Claudia

2008 "Los dispositivos recientes de empleo juvenil: institucionalidades, articulaciones con la educación formal y socialización laboral". Revista del Trabajo - Nueva Época. 4(6): 123-142.

JACINTO, Claudia

2010 "Veinte años de formación para el empleo de jóvenes vulnerables en América Latina: persistencias y reformulaciones" en C. Jacinto (Comp.), La construcción social de las trayectorias laborales de jóvenes. Políticas, instituciones, dispositivos y subjetividades. Buenos Aires: Teseo - IDES, 119-148.

KESSLER, Gabriel

2002 La experiencia escolar fragmentada. Estudiantes y docentes en la escuela media en Buenos Aires. Buenos Aires: IIPE-UNESCO.

MARTÍN CRIADO, Enrique

1999 "El paro juvenil no es el problema, la formación no es la solución" en L. Cachón Rodríguez (Coord.), Juventudes, mercados de trabajo y politicas de empleo. Valencia: 7imig, 15-47.

MARTÍNEZ LÓPEZ, Antonio

2009 "Los orientadores laborales. Trabajo cotidiano y efectos sobre sus públicos". Cuadernos de Relaciones Laborales, 27(2): 145-169.

MANZANO, Virginia

2007 "Del desocupado como actor colectivo a la trama política de la desocupación. Antropología de campos de fuerzas sociales", en M. C. Cravino (Ed.), Resistiendo en los barrios: Acción colectiva y movimientos sociales en el Área Metropolitana de Buenos Aires, Los Polvorines: UNGS, 101-134.

MAUSS, Marcel

2009 Ensayo sobre el don. Forma y función del intercambio en las sociedades arcaicas. Katz: Buenos Aires.

MÍGUEZ, Daniel; ISLA, Alejandro

2010 Entre la inseguridad y el temor. Instantáneas de la sociedad actual. Buenos Aires: Paidós. 
MORENO NAVARRO, Isidoro

1997 “Trabajo, ideologías sobre el trabajo y culturas del trabajo". Trabajo. Revista andaluza de relaciones laborales, 3: 9-28.

NEFFA, Julio C.

2012 Empleo, desempleo y políticas de empleo. De las políticas pasivas a las políticas activas de empleo. Análisis comparativo (1989.2011). No. 10. Segundo trimestre. Buenos Aires: CEIL-PIETTE.

NEFFA, Julio C.; OLIVERI, María L.; PERSIA, Juliana

2010 "Transformaciones del mercado de trabajo en la Argentina: 1974-2009" en J. Neffa; J.C. Panigo y P. E. (Comps), Transformaciones del empleo en Argentina. Estructura, dinámica e instituciones. Buenos Aires: CICCUS, 19-52.

NOVELO, V.; GÓMEZ, M. A.; CASTRO, A.H.

1986 "Propuestas para el estudio de la cultura obrera". Nueva Antropología 29: 65-84.

PALENZUELA Palencia, Pablo

1995 "Las culturas del trabajo. Una aproximación antropológica". Sociología del Trabajo, 24: 3-28.

PÉREZ, Pablo

2006 "Tensiones entre la política macroeconómica y la política de ingresos en la Argentina Post-convertibilidad". Laboratorio: Estudios sobre Cambio Estructural y Desigualdad Social, 7(19): 5-12.

2010 “Por qué difieren las tasas de empleo de jóvenes y adultos? Un análisis de transiciones laborales en Argentina post-Convertibilidad" en J.C. Neffa, D. Panigo y P.E. Pérez (Comps), Transformaciones del empleo en Argentina. Estructura, dinámica e instituciones. Buenos Aires: CICCUS, 77-104.

2013 "Inserción laboral juvenil y políticas públicas de empleo en Argentina", Revista Juventude.br, Centro de Estudos e Memória da Juventude (en prensa): s/d.

ROSEBERRY, William

2002 "Hegemonía y lenguaje contencioso", en G. M. Joseph y D. Nugent (Comps.), Aspectos cotidianos de la formación del estado. La revolución y la negociación del mando en el México moderno. México DF: Ediciones Era, 213-226.

SALVIA, Agustín

2008 "Introducción. La cuestión juvenil bajo sospecha" en A. Salvia, Agustín (Comp.). Jóvenes promesas. Trabajo, educación y exclusión social de jóvenes pobres en la Argentina. Buenos Aires: Miño y Dávila, 13-32.

2013 "Juventudes, problemas de empleo y riesgos de exclusión social. El actual escenario de crisis mundial en Argentina". Friedrich-Ebert-Stiftung. Berlín, 1-16.

SAYER, Derek

2002 "Formas cotidianas de formación del estado: algunos comentarios disidentes acerca de la 'hegemonía'”, en G.M. Joseph y D. Nugent (Comps), Aspectos cotidianos de la formación del estado. La revolución y la negociación del mando en el México moderno. México DF: Ediciones Era, 227-238. 
SHORE, Cris

2010 "La antropología y el estudio de la política pública: reflexiones sobre la "formulación' de las políticas”. Antípoda. Revista de Antropología y Arqueología, 10: 21-49.

THOMPSON, Edward Palmer

1991 Costumbres en común. Barcelona: Editorial Crítica-Grijalbo Mondadori.

WEBER, Max

2006 La ética protestante y el espiritu del capitalismo. La Plata: Terramar.

\section{Fuentes}

Resolución 497 del Ministerio de Trabajo, Empleo y Seguridad Social de la Nación Argentina, 13 de Mayo de 2008. 